\title{
Ageing management in NPP. Effectiveness of the methods for control, examination and monitoring in relation to mechanisms of degradation of mechanical properties
}

\author{
Galya Dimova ${ }^{1, *}$ \\ ${ }^{1}$ Kozloduy NPP EAD, ICC-DCC, 3321 Kozloduy, Bulgaria
}

\begin{abstract}
This paper describes ageing management activities for Long Term Operation (LTO) of components of Kozloduy NPP EAD. The stages of LTO Project are: Stage 1 - implementing a comprehensive assessment of the actual condition of the equipment; Stage 2 - providing of a Complex Analysis; Stage 3 - licensing of Plant Life Extension (PLEX) for long-term operation (LTO). The main activities are assessment of actual condition of the equipment and building; review of methods for control (nondestructive), examination and monitoring; assessment of effectiveness of methods; necessity of additional control/ examination/ service. The paper describes some mechanisms of degradation of mechanical properties, methods for control and criterions for their effectiveness.
\end{abstract}

\section{Introduction}

Many nuclear power plants (NPPs) around the world have been operating for over 30 years. As of October 2016, of all the 450 NPPs in operation, 79 have been operated for over 40 years, while the service life of 182 ones has exceeded 30 years, (https://www.iaea.org/pris), Fig.1. The operating design life of Nuclear Power Plants (NPPs) is normally 30-40 years, [1].

The possibilities for plant life extension (PLEX) of nuclear power plants are demonstrated through analyses, tests and lifetime management for the expected long-term operation (LTO). Thus, it is of great importance to perform assessment and upgrading of the safety measures for LTO.

The subject of this paper concerns lifetime management and plant life extension of the NPP power units. More specifically, it arises from the implementation of forthcoming PLEX activities on units 5 and 6 at Kozloduy NPP (KNPP). The design life of unit 5 expires in 2017, and of unit 6 - in 2019. Since 2010, the plant has undertaken a large-scale PLEX project for comprehensive assessment of equipment and lifetime extension of the power units 5 and $6,[2]$. The PLEX project has been subdivided in the following stages:

Stage 1 - performing of a comprehensive assessment of the current condition of equipment and buildings (ageing management review) (2010-2013), [3].

\footnotetext{
*Corresponding author: gdimova@npp.bg
} 
Stage 2 - performing of comprehensive analyses of equipment (structures, systems and components, SSCs) (2011-2015).

$>\quad$ Stage 3 - licensing by the Bulgarian Nuclear Regulatory Agency (BNRA) (licence application submitted in 2016 for unit 5).

Total Number of Reactors: $\mathbf{4 5 0}$

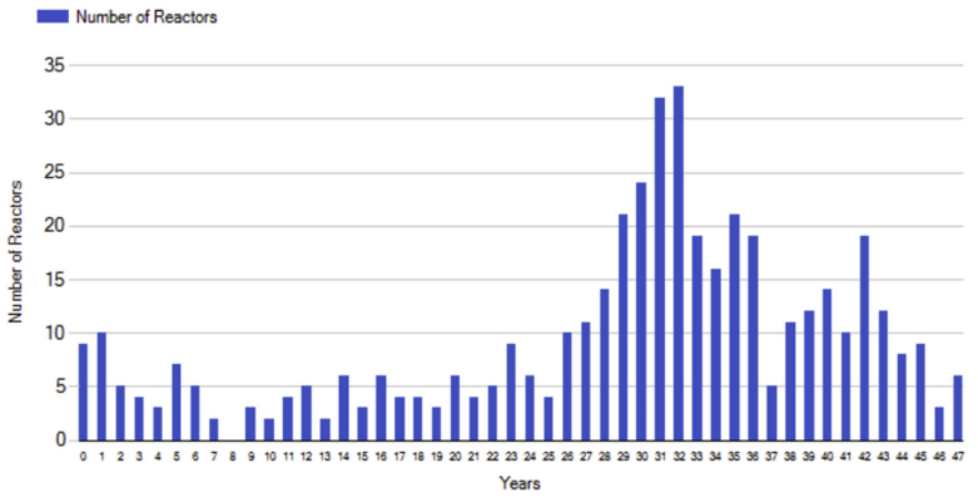

Fig. 1. Number of reactors / Years in operation.

For each power unit, additional service life of 30 years is envisaged. The standards and good practices of the International Atomic Energy Agency (IAEA) require that comprehensive activities be implemented for ageing management of SSCs, [4, 5]. The process of ageing management of components starts as early as a decision has been made for LTO, and lasts to the end of the service life of the nuclear power plant. New build NPPs are required to have ageing management in place as of the beginning of operation. The process of ageing management comprises the following stages:

$>$ Selection (screening) is implemented of components important to safety and whose residual life needs to be assessed.

$>\quad$ The dominant ageing mechanisms are identified for the selected components, and evaluation follows of the existing efficient practical methods (or new ones are developed) for ageing process monitoring or mitigation.

The selected components lifetime is managed through implementation of effective practices and initiatives associated with correct designing, manufacturing, storage, monitoring, surveillance, maintenance and operation.

Kozloduy NPP has in place a system of maintenance and repair used in carrying out the scheduled annual outages of equipment and pipelines, maintenance activities, conditionbased maintenance and corrective (breakdown) maintenance, [6]. The maintenance and repair system serves to keep and enhance the reliability of equipment through limiting the degradation on the functioning systems, or the systems are restored to an acceptable level in order to proceed with the performance of their design functions. The methods utilised for maintenance and repair have to ensure support of the design functions assigned to the facility, and preserve its operability to the end of the service life envisaged. Evaluating the effectiveness of the maintenance and repair methods as regards the active degradation mechanisms focuses on whether they support/enhance the reliability of equipment. It is especially important for making a responsible decision for extending the operating life of the power units.

The purpose of this paper is to provide a general overview of the maintenance and repair activities, and on the manner of evaluating the effectiveness of the maintenance and repair methods. The body of this paper describes (some of the) degradation mechanisms (or 
the physical-chemical processes within materials) occurring under the impact of the operating conditions. Descriptions are also provided of the maintenance and repair approaches and methods used for periodic monitoring of the changes in materials' mechanical properties, and loss of resilience of the operating systems. There are no documented effectiveness criteria for the maintenance and repair methods on nuclear power plants, but a great deal of relevant operating experience has been accumulated. The facts reported in this paper regard the mechanical equipment of the main components and systems in the primary circuit.

\section{Degradation of mechanical properties, maintenance and repair methods, and evaluation of their effectiveness}

\subsection{Corrosion-erosion processes}

The corrosion-erosion processes that are typical for NPPs consist in corrosion destruction of materials followed by erosion wear caused by the flow of fluid, [7]. Factors affecting the process include the fluid composition, velocity and temperature, the component material and geometry, the active stresses, the periodicity of surface moisturising/drying. Local corrosion typically occurs in steam generators (SGs) and reactor sealing surfaces, pressurisers, and emergency core cooling systems (ECCS). Intergranular corrosion typically affects reactor pressure vessels (RPV) and steam generators; corrosion fatigue occurs in steam generators and pressurisers; stress corrosion - in reactors, SG heat exchanger tubes, and pipelines in the pressuriser system and ECCS. Stresses in the pipe bend areas will lead to a considerable change in the metal electrode potential. Tensile stresses (tensions) shift the electrode potential to the negative side, while the compressive stresses shift it to the positive side. The stretched sections act as anodes with regard to the rest of the metal and degrade most intensively. The equipment loss of function or change of its design functions is manifested through: wall thickness.

Increased probability of a leak upon break of pipelines caused by reduced pipe-

$>$ Elevated frequency of failures due to stress changes within the materials of the systems.

$>$ Occurrence of abnormal operating conditions as a result of loss of tightness.

$>$ Occurrence of abnormal operation of the heat exchangers resulting from heat exchanging tubes rupture.

$>$ Deterioration of heat exchange in case of presence of sludge/deposits.

$>$ Elevated radioactivity levels due to activation of the corrosion products.

The maintenance and repair activities comprise: 1) water chemistry measures implementation and maintenance; 2) performing a corrosion survey in search for the presence of sludge/deposits; 3 ) conducting of in-service inspection (ISI) through visual, dye penetrant, eddy current, and mechanical tests, ultrasonic thickness measurement of the pipe bends, bended sections, or at the outside formation of pipe bends. The effectiveness of the maintenance and repair methods regarding corrosion-erosion damage appears in terms of the following two focus areas: 1) water chemistry control (water chemistry metrics shall correspond to the normative values; all deviations from the norms shall be corrected within the timelines adopted; violations of water chemistry norms such that may lead to the power unit abnormal operation, shall be prevented; 2) conduct of non-destructive testing combined with timely finding and repairing of any discontinuities in the metal and welded joints, or wall thinning, to prevent failure of the element or avoid degradation of its functions. 


\subsection{Neutron embrittlement}

Neutron embrittlement of the reactor pressure vessel metal occurs as a result of intensive neutron flux under high temperature and pressure conditions. Upon reacting with the substance, neutrons may either transfer their energy to atoms through elastic impacts, or serve as the source of charged particles formation, [8]. Such processes will impair the correct position of atoms within the metal crystal grid and this will cause defects formation. The density of radiation defects is subject to the type of radiation, its parameters and on the nuclear-physical characteristics of the material. The spot defects that occur - vacancies, internodal atoms, embedded atoms, etc., at sufficiently high temperatures can recombine, migrate to volumetric or surface leakages (dislocations, grain boundaries), formation of radiation stacking faults in the shape of pores and dislocation nodes. The irradiation of metal with fast neutrons results in microscopic areas of structural damages with high concentration of spot defects. Neutron embrittlement affects the reactor pressure vessel, barrel and core baffle, and reactor guard-tube bank. The influencing factors include the neutron flux values and direction, and the material chemical composition. The elevated levels of nickel (Ni) and manganese (Mn) in RPV steel grades enhance embrittlement due to the formation of $\mathrm{Ni}-\mathrm{Mn}-\mathrm{Si}$ clusters (dislocation nodes), while silicon ( $\mathrm{Si}$ ) reduces embrittlement. Fig. 2 shows microscope photos of samples with varying weight percentage of Ni (sample parts $0,22 C u-x N i-1,6 \mathrm{Mn}$ ), subjected to neutron flux irradiation, with neutron energy exceeding $1,6 \mathrm{MeV}$ at temperature of $T=290 \div 310^{\circ} \mathrm{C}$, [9].
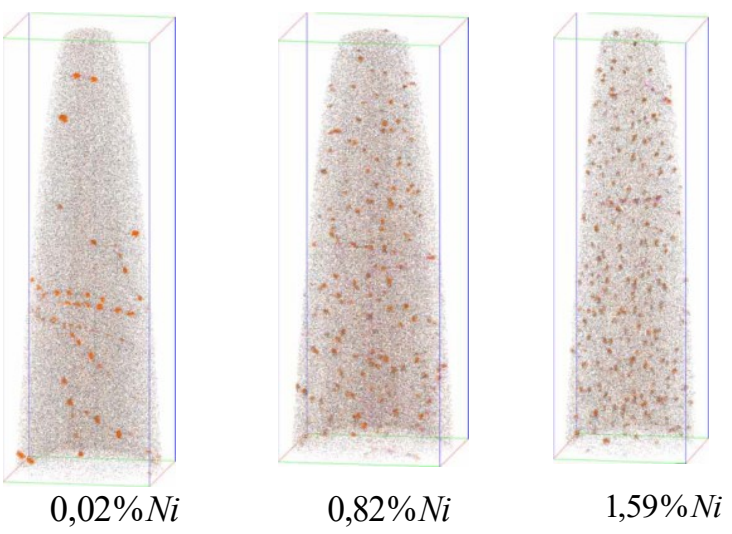

Fig. 2. Dislocations forming in samples with varying weight percentage of $\mathrm{Ni}$ $(0,22 \mathrm{Cu}-x \mathrm{Ni}-1,6 \mathrm{Mn})$ at temperature of $\mathrm{T}=290 \div 310^{\circ} \mathrm{C}$.

The neutron embrittlement of ferritic steels is manifested as increase of $\Delta T_{k F}$ of the critical temperature value of radiation embrittlement, $T_{\kappa}$, [8,9]. Neutron embrittlement elevates the probability of brittle fracture of metals, especially of the RPV welded joints located opposite the core; it also increases the probability for changes occurring in the shape of components (core barrel and baffle). The maintenance and repair preventive measures include:

$>\quad$ Use of low-leak schemes of core refuelling.

$>$ Calculating the neutron flux values following each fuel cycle.

For $15 \mathrm{Kh} 2 \mathrm{HMFAA}$ steel types, the neutron flux limit is $5,7 \times 10^{22} \mathrm{n} / \mathrm{m}^{2}$ for the RPV metal, and this is a limiting factor for the facilities' safe operation. Within certain time 
intervals, calculations and analyses are performed of the critical temperature of irradiation embrittlement $T_{\kappa}$ and the mechanical characteristics are studied of units 5 and $6 \mathrm{RPV}$ surveillance specimens. In-service inspection of metal is performed using visual, dye penetrant, and ultrasonic tests, [10]. Periodic thermohydraulic and strength analyses are conducted in order to assess the defects' propagation resistance. The maintenance and repair efficiency criteria are required to exclude the probability of RPV metal brittle fracture as a consequence of radiation embrittlement, or due to the presence of a defect. The radiation embrittlement critical temperature variation $\Delta T_{k F}$ needs to be within the design limits. Any discontinuities of metal or welded joints need to be detected and repaired in a timely fashion in a way such as not to lead to a failure of the element, or affect any of its functions.

\subsection{Cyclic fatigue of metals}

Degradation under the impact of cyclic (fatigue) loads occurs due to the action of variable stresses and deformations; gradually, changes of metal accrue in a way such that leads to change of properties, formation of cracks, their development resulting in the eventual degradation of the object. The fatigue degradations of metal of NPP facilities can be highcycle fatigue and low-cycle fatigue, as well as thermal fatigue occurring due to the cyclic changes of the thermal field.

Cyclic fatigue affects reactors, steam generators, pressurisers, pipelines of the pressuriser system; main circulation pipelines and emergency core cooling systems. Corrosion fatigue can also be observed and it affects steam generators and pressurisers. The value and direction of the effective stresses, and the number of actually implemented cycles compared with the design ones are factors that influence fatigue. The growing number of cycles enhances the probability of metal degradation by fatigue. Cyclic fatigue preventive measures comprise:

$>\quad$ Regarding the RPV metal - analysis of surveillance specimens, [11].

$>$ Performing of in-service inspection of metal using visual, dye penetrant, eddy current, and ultrasonic tests.

$>$ Conduct of hydraulic testing.

The maintenance and repair effectiveness criteria require that:

$>$ For each facility, the load cycles should be registered and controlled under different design modes, in a way such that no failure of the element or degradation of its functions occurs.

$>$ Strength analyses should be conducted.

$>$ Any discontinuities in metal or welded joints should be found and repaired in due time.

\subsection{Thermal embrittlement}

Materials feature different ageing mechanisms. In metal alloys, ageing depends on the degradation of saturated solid solutions. Thermal embrittlement affects reactors, steam generators, pressurisers, pipelines of the pressuriser system; main circulation pipelines and pipelines of the emergency core cooling systems. Thermal embrittlement is affected by factors such as the working temperature values and the time (duration) of the facility's operation. Fig. 3 illustrates the dependence of the critical temperature $\Delta T k(t)$, on the time of operation $t$ for two number of units - a and $b$. Peak values of the critical temperature $\Delta \operatorname{Tk}(\mathrm{t})$ are observed with regard to the time period of the $3 \div 5$ years of the facility 
operation; after the elapse of this period, the impact on embrittlement of the thermal component decreases while the neutron one increases.

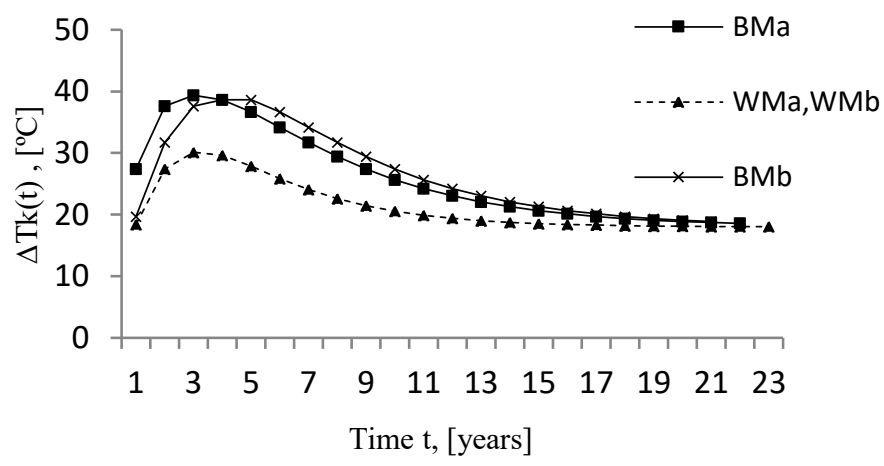

Fig. 3. Dependency of $\Delta T_{K}(t)$ on time $t$ (or thermal inducted part of $\Delta T_{K}$ ) for base metal, BMa and $\mathrm{BMb}$, and weld metal, WMa and $\mathrm{WMb}$.

The maintenance and repair preventive measures cover:

$>$ Regarding the RPV metal, the mechanical properties of the surveillance specimens have to be studied.

$>$ In-service inspection (ISI) of metal, using visual, radiographic and metallographic tests, needs to be undertaken.

Hydraulic tests have to be performed on pressure vessels.

Thermal embrittlement increases the probability of the facilities brittle fracture. The maintenance and repair effectiveness criteria require that:

$>$ The metals mechanical properties be retained.

$>$ Any discontinuities of metal or welded joints need to be detected and repaired in a timely fashion, in a way such as not to lead to a failure of the element or affect any of its functions.

\subsection{Wear}

Multiple studies have demonstrated that the process of gradual loss of functionality of components in operation can be subdivided in three stages: 1) stage of adjustment, 2) normal operation stage, and 3) wear, caused by the facilities normal operation, Fig. 4, [7].

Throughout the stage of adjustment (1) mutual changes occur in the macro- and microgeometry of the working faces, and products of wear and oxidation are formed. The working faces wear rather intensively during this stage. Gradually, wear weakens and stabilises to a stage of normal operation wear (2). This stage (2) overlaps with the power unit design life. Once an energy limit has been exceeded the oversaturated solid solutions start to disintegrate, the wear value progressively increases (3), the components functioning deteriorates and the need of repair arises. Stage (3) usually occurs towards the end of the design life of the facilities. 


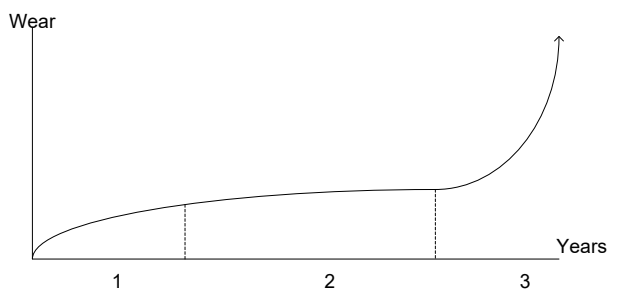

Fig. 4. Stages of wear in the course of the equipment operation, Stage (1) - wear during adjustment, Stage (2) - wear during normal operation, Stage (3) - wear in the end of the facility operating lifetime.

The process of wear affects hydraulic snubbers, sealing faces, fixing elements, internal parts of cylindrical vessels and pipelines. The rate of wear is affected by the following factors:

$>$ Combination of materials for the working surfaces.

$>$ Physical, chemical and mechanical properties of the surfaces subjected to friction.

$>$ Interactions of the working surfaces with the environment.

$>$ Clean processing of the friction surfaces.

$>$ Type of friction (dry, border, semi liquid, liquid).

$>$ Values of the normal pressure and the velocity of working surfaces one against the other.

Of the large number of wear types concerning the working surfaces of machine parts, major importance is attached to abrasive wear in the presence of grease, because the wear products that invariably arise from the machine components friction are oxidised and turn into a sort of abrasive materials. For instance, under normal operating conditions, the hydraulic snubbers components are subjected to negligible loads, and the hydraulic snubber may stop performing its functions. With degradation due to wear, a hydraulic snubber is incapable of performing its protective functions in case of strong vibrations, or an abrupt displacement of equipment caused by seismic loads. In the course of operation, wear affects pins (their cylindrical part) and pin sockets. The mechanical properties degradation deteriorates the fixing function and there exists a possibility that the facility be untight. Preventive measures in this case comprise visual inspection during maintenance. The criterion for effectiveness of the maintenance and repair methods in case of wear consists in preventing wear processes to a degree that may affect the equipment functionality.

\section{Maintenance and repair programmes for NPP components and systems}

The facilities and components of an NPP are covered in programmes for maintenance and repairs. They envisage activities for equipment control, testing and monitoring; the control and monitoring methods focus on prevention of the consequences from inherent degradation mechanisms on the metal mechanical properties. The programmes are usually developed in accordance with Russian rules and norms for safe operation of NPP facilities and pipelines, [12] and with type control programmes, [13]. The data obtained as a result of implementing the maintenance and repair programmes serve for assessment of the current state of components and equipment, and for operational purposes - to allow the facility to be returned to service; as well as for general purposes - implementing of design modification of the facility, modernisations, or for lifetime extension. Irreplaceable 
equipment and a great part of the replaceable equipment are subject to technical condition assessment and ageing management for further (long-term) operation.

The first stage of the PLEX project consists of a comprehensive assessment of the current condition (ageing management review) of the equipment, [11]. Table 1 shows monitored ageing mechanisms and respective parameters that determine the metal condition. On the basis of the key parameter a criterion is derived for assessment of the facility condition.

Table 1. Metal ageing mechanisms and parameters characterising its condition.

\begin{tabular}{|l|l|}
\hline \multicolumn{1}{|c|}{ Monitored metal ageing mechanism } & Key parameter characterising metal condition \\
\hline Mechanical properties change & $\begin{array}{l}\text { Strength limit, creep limit, relative elongation, } \\
\text { relative shrinking, hardness number, KCV } \\
\text { (impact toughness) }\end{array}$ \\
\hline Structural changes & Content of phases, grains and micropores \\
\hline Cracking & Geometrical dimensions of discontinuities \\
\hline Erosion & Damaged area; wall thickness \\
\hline Pitting & $\begin{array}{l}\text { Number of damages per unit area and depth of } \\
\text { damages }\end{array}$ \\
\hline
\end{tabular}

During stage 1 of the units 5 and 6 PLEX project an assessment was made of the effectiveness of maintenance and repair methods. The metal condition is evaluated by considering the resistance to the degradation mechanisms of mechanical properties typical for NPPs. During the second stage of the PLEX project, analyses are performed of the structural integrity of facilities. Fig. 5 demonstrates the complete process of comprehensive engineering assessment of components and equipment of KNPP units 5 and 6 . The assessments input data are derived from equipment passport data, design requirements, discontinuities data, defects, failure data, accidents, operating conditions, ambient conditions and cycles of work. Analyses are generated for static and dynamic strength and seismic stability.

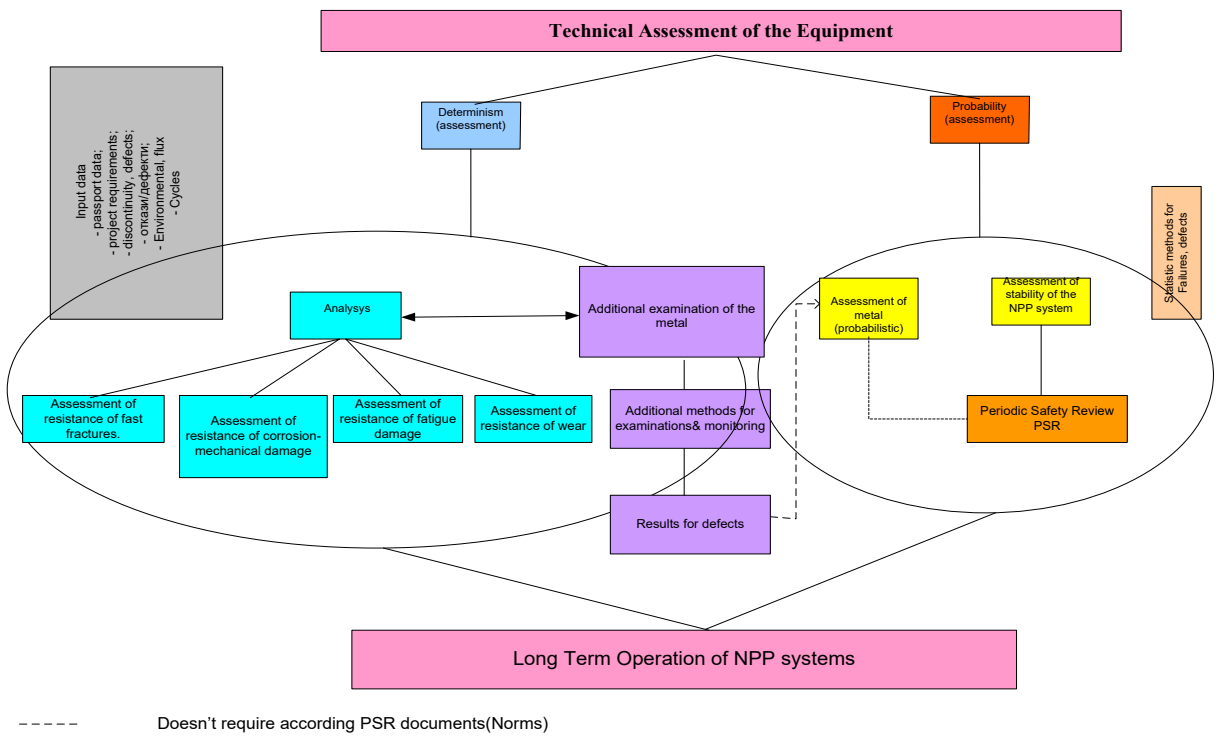

Fig. 5. Lifetime extension process for NPP components and facilities 
The analyses should contain sufficient data to allow drawing of conclusions on the residual lifetime of the respective facility.

For all the main types of facilities, analyses need to be performed selecting the circulation loop or facility with the highest load. Based on the comprehensive condition assessments issued at PLEX project Stage 1, and the analyses completed during the project Stage 2, conclusions have been drawn on the facilities' residual lifetime, and final reports issued on the lifetime extension feasibility.

Following the analyses and before making the final decision for lifetime extension of the units, assessments should be conducted on the operational safety, and the probabilistic safety analysis (PSA) updated. The nuclear power plant performs a self assessment of safety, while the LTO licence is issued by the BNRA.

\section{Conclusions}

The PLEX project first and second stages are now complete for unit 5, while Stage 2 for unit 6 is currently under way. The maintenance and repair methods effectiveness has been assessed. The procedures and scope of control, testing and monitoring in place allow timely identification and recovery of defects that may lead to a failure of the element, or affect its operability. The maintenance and repair system ensures the required level of reliability and operability of elements. Before LTO, however, some components necessitate a further survey (the QF system buried pipelines, fire protection pipelines of the UJ system, supports, hydraulic snubbers, ventilation stack, reactor refuelling machine, etc.). For the equipment that is not part of the standard maintenance and repair programmes, additional programmes for a single-time metal condition survey are being prepared.

In documents such as conclusions on the condition of equipment, or final reports on PLEX, recommendations are provided for certain components to ensure future safe operation of the facility during the LTO period. Measures such as those listed below are being planned:

$>$ Conduct of regular periodic control.

$>$ Conduct of a single-time control of the mechanical characteristics after, for example, 10 years of operation. Such a measure is envisaged in case some of the operational load modes of the facility (hydraulic tests, or an emergency situation) cause the stresses to exceed the limits permitted.

\section{References}

1. R. Krivanek, J. Fiedler, Nucl Eng Des Journal, 316 (2017)

2. OAO OKB Gidropress, General programme for comprehensive assessment of the actual condition and assessment of the residual lifetime of SSCs at Kozloduy NPP unit 5, within the design range of $O A O O K B$ Gidropress (Russia, 2012)

3. OAO OKB Gidropress, Report on the results from the comprehensive assessment of the actual condition and assessment of the residual lifetime of equipment and pipelines of the reactor unit at Kozloduy NPP unit 5, within the design range of OAO OKB Gidropress, (Russia, 2013)

4. IAEA, IAEA Safety Standards Series NS-G-2.12 (Austria, 2009)

5. IAEA, Ageing Management for Nuclear Power Plant: International Generic Ageing Lessons Learned, IGALL, Safety Reports Series 82 (Austria, 2015)

6. KNPP, Long-term schedule for preventive maintenance and repair of SSCs belonging to the safety systems and systems important to safety at units 5 and 6 and the common plant facilities; 08.30.0CO.00.ГP.039/1 (Bulgaria, 2008) 
7. V. Ostreykovskiy, Materials ageing in nuclear energy (Russia, 2000)

8. M. Georgiev, Cracking resistance of metals under static loads (Bulgaria, 2005)

9. A. Nomoto, Understanding on the Mechanisms of Irradiation Embrittlement of RPV Steels and Development of Embrittlement Correlation Method; Central Research Institute of Electric Power Industry (CRIEPI) (Japan, 2014)

10. KNPP, ISI Procedure for base metal, welded-on surfaces and welded joints in equipment and components of WWER-1000 reactor types at Kozloduy NPP (Bulgaria, 2016)

11. Kurchatovskij Institute, Close-out Report on Contract No 292000008, Testing and study of surveillance specimens set $3 L$ of unit $5 R P V$, and set $2 L$ of unit 6 RPV at Kozloduy NPP EAD, Stage I; $3 L$ at unit 5 (Russia, 2015)

12. HП-084-15 Federal norms and regulation for use of atomic energy. Regulations on the in-service inspection of base metal, welded joints and welded-on surfaces of equipment, pipelines and other elements of nuclear power plants (Russia, 2015)

13. Type programme for ISI of the condition of base metal and welded joints of equipment and pipelines at NPPs with WWER-1000 (Russia, 2009) 